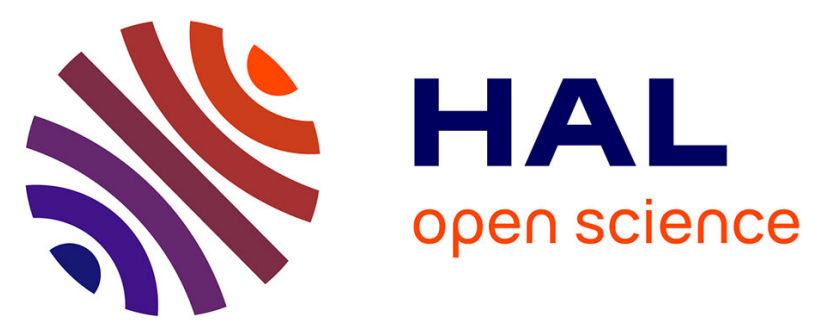

\title{
The importance of fracture-healing on the deformation of fluid-filled layered systems
}

Anna Vass, Daniel Koehn, Irfan Ghani, Sandra Piazolo, Renaud Toussaint

\section{To cite this version:}

Anna Vass, Daniel Koehn, Irfan Ghani, Sandra Piazolo, Renaud Toussaint. The importance of fracture-healing on the deformation of fluid-filled layered systems. Journal of Structural Geology, 2014, 67, pp.94-106. 10.1016/j.jsg.2014.07.007 . hal-01198604

\section{HAL Id: hal-01198604 \\ https://hal.science/hal-01198604}

Submitted on 26 Sep 2015

HAL is a multi-disciplinary open access archive for the deposit and dissemination of scientific research documents, whether they are published or not. The documents may come from teaching and research institutions in France or abroad, or from public or private research centers.
L'archive ouverte pluridisciplinaire HAL, est destinée au dépôt et à la diffusion de documents scientifiques de niveau recherche, publiés ou non, émanant des établissements d'enseignement et de recherche français ou étrangers, des laboratoires publics ou privés.

\section{(ㅇ)(1) $\$$}

Distributed under a Creative Commons Attribution - NonCommercial - NoDerivatives| 4.0 
3 Anna Vass*

4 School of Geographical and Earth Sciences, University of Glasgow, Lilybank Gardens, G12

5 8QQ, Glasgow, UK.

$6 \quad$ Tel.: +44 (0)1413305469

$7 \quad$ E-mail: a.vass.1@,research.gla.ac.uk

8

9

10

Daniel Koehn

11 School of Geographical and Earth Sciences, University of Glasgow, Lilybank Gardens, G12

12 8QQ, Glasgow, UK.

13 E-mail: Daniel.Koehn@glasgow.ac.uk

14

15

16

17 Tektonophysik, Institut für Geowissehschaften, Johannes Gutenberg Universität Mainz,

18 Germany

19 E-mail: geo_irfan@hotmail.com

20

21

22

23 Australian Research Council Centre of Excellence for Core to Crust Fluid Systems/GEMOC,

24 Department of Earth and Planetary Sciences, Macquarie University, NSW 2109, Australia

25 E-mail: sandra.piazolo@mq.edu.au

26

27 Renaud Toussaint

28 Institut de Physique du Globe de Strasbourg, UMR 7516, Université de Strasbourg/EOST, 29 CNRS, 5 rue René Descartes, 67084 Strasbourg Cedex, France.

30 E-mail: renaud.toussaint@unistra.fr

31

32

33

34

Keywords: hydro-mechanical model, hydrofracturing, healing, vein strength, elastic modulus 


\section{Abstract}

Understanding the fracturing-healing-refracturing cycle is a fundamental part of studying the

37 deformation dynamics and the permeability evolution of the rock systems. Previous studies, however, have not examined the influence of healing and the mechanical properties of the healed fractures (veins) on the rock deformation. We present results from a two-dimensional coupled hydro-mechanical model which simulates large time and spatial scale dynamic fracturing and healing of a porous medium under the influence of gravity, tectonic stretching and elevated fluid pressures. Our results show that healing decreases the local porosity, and that the veins' strength is more important than their elastic modulus in influencing the deformation and the evolving patterns. Hard veins, such as quartz or ore, make the aggregate progressively stronger, which leads to an overall healing of the system, limited fracturing and thus fluid flow, greater stresses and delayed saturation. Weak veins, such as calcite, make the system weaker in which refracturing of the healed bonds is the dominant process that creates more open fractures and thus increases the permeability. These results provide clues for the importance of the veins' mechanical properties and can enhance our understanding of the deformation dynamics and the permeability evolution of the rock systems.

\section{Introduction}

Fluids play an important role in a lot of processes in the Earth's crust. The circulation of

54 fluids is primarily responsible for mass and energy transport, and the formation of 55 hydrothermal ore deposits (Fyfe et al., 1978). Fluid has also been recognized as an important 56 factor in triggering earthquakes, reactivate faults and in general influence processes that control the deformation of rocks (Hubbert and Willis, 1957; Hubbert and Rubey, 1959; Putnis and Putnis, 2007; Putnis and Austrheim, 2010). 
Local fluid overpressure within a rock suite can trigger fracturing. This process is known as hydrofracturing and can be either induced or natural. Induced hydrofracturing has been used as a well stimulation process to enhance the well productivity by fracturing the surrounding rock and induce fluid flow towards a well (Shapiro and Dinske, 2009; Caló et al., 2013; Shalev et al., 2013). Natural hydrofracturing is based on similar principles and occurs when the natural system has a local overpressure. The process is recognized as an important fracturing mechanism in rocks (Engelder and Lacazette, 1990; Hunt, 1990; Bruno and Nakagawa, 1991; Hurst et al., 2005; Rodrigues et al., 2009; Nermoen et al., 2010).

Fluid overpressure can be induced by a variety of processes and is generally linked to a local increase in fluid volume due to for example dewatering mechanisms, thermal expansion of fluid, hydrocarbon generation or general density driven movement of fluid (Fyfe et al., 1978; Bethke, 1985; Oliver, 1986; Oliver, 1996; Swarbrick et al., 2002; Cox, 2005, Vinningland et al., 2007; Johnsen et al., 2008a and 2008b). High pressure gradients that lead to fracturing are generally developing in heterogeneous systems, for example below or across seals or along fracture and fault systems. Elevated fluid pressures induce seepage forces that can locally modify the principal stresses (Mourgues and Cobbold, 2003; Cobbold and Rodrigues, 2007; Rozhko et al., 2007; Rozhko, 2010) especially in combination with anisotropies of the mechanical properties and heterogeneities in a rock (Cornet and Valette, 1986; Hu and Angelier, 2004).

The propagation of hydrofractures depends mainly on three factors, the (1) magnitude and orientation of fluid pressure gradients relative to tectonic and gravitational stresses, (2) mechanical properties of rocks and (3) discontinuities of a given system (Cook and Gordon, 1964; Cooke and Underwood, 2001; Smith et al., 2001; Brenner and Gudmundsson, 2004; Cooke et al., 2006; Gu and Siebrits, 2008; Ghani et al., 2013). When fracture propagation is favored, the fractures themselves provide pathways for fluids and therefore control fluid flow 
84 (Cox, 2005). In addition, fractures may close (heal) when material precipitates within them

85 forming veins (Fig. 1), which decreases the permeability of the rock and limits the fluid flow again (Bons et al., 2012). Tenthorey et al., (2003) argue that healing of fractures and faults

87 has two significant and competing effects on the system. First of all, it can strengthen the aggregate by increasing cementation and cohesion, which directly causes permeability decrease. Second of all, it simultaneously weakens the system as the low permeability can result in elevated fluid pressure that in turn can cause further failure. Understanding fluid

91 flow and the permeability evolution of the rock is crucial in many disciplines such as 92 hydrocarbon and water supply exploration, waste disposal or mining. Dynamics of 93 (hydraulic) fracturing, healing and refracturing of rocks are still poorly understood.

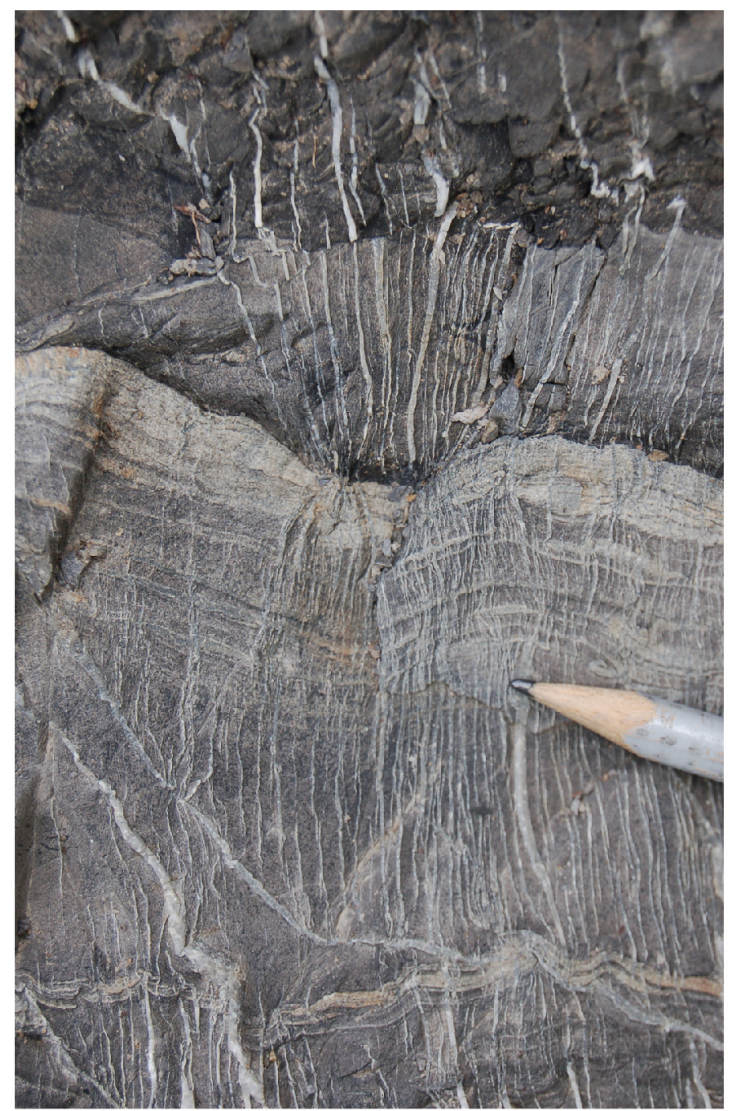

b

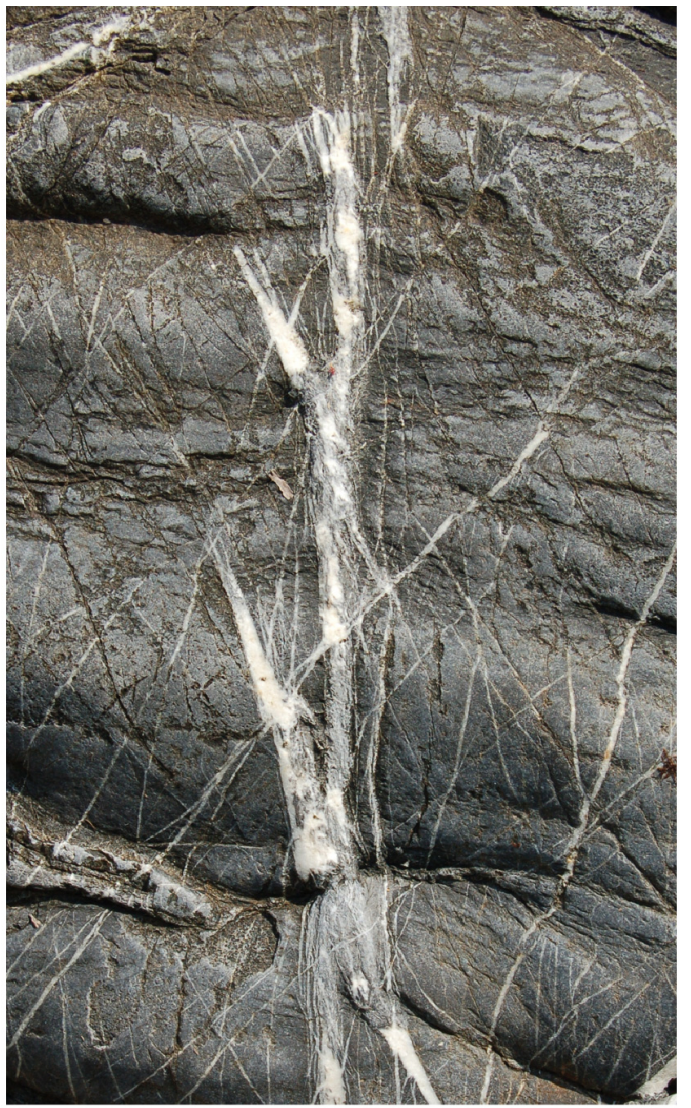

Fig. 1. Field examples of veins in the Internal Ligurian Units near Sestri Levante, Italy. Intense veining is shown on (a), where the veins are relatively hard and the rock (shale) is soft. (b) Hard rock (sandstone) is cut by several soft veins along which multiple refracturing events can be observed. 

nature have provoked the development of several numerical models (Tzshichholz et al., 1994;

97 Dahm, 2000, McNamara et al., 2000; Flekkøy et al., 2002; Johnsen et al., 2006; Olson et al., 2009; Goren et al., 2010; Niebling et al., 2010a and 2010b; Goren et al., 2011; Wangen, 2011, Niebling et al., 2012; Aochi et al., 2013; Ghani et al., 2013 and 2015). The different models face the same complexity as hydrofracturing involves (1) elastic deformation of the matrix triggered by fluid pressure, (2) fluid flow inside matrix and fracture and (3) fracture propagation (Adachi et al., 2007). Many numerical simulations demonstrated that the porosity and the mechanical failure of the media are crucial in the initiation and propagation of the hydrofractures (e.g. Flekkøy et al., 2002; Johnsen et al., 2006; Olson et al., 2009; Goren et al., 2010; Nermoen, et al.; 2010). However, most of these models lack the intimate coupling between the fluid diffusion and deformation, as well as real (scaled) values. Their spatial and temporal resolutions are limited, they mostly deal with granular media and they do not consider healing of fractures. These limitations provided inspiration for further work in terms of numerical modeling.

This paper is a continuation of the work by Ghani et al. (2013 and 2015) who presented a 2D coupled hydro-mechanical model through which the dynamics of layered porous systems were examined. In this contribution, we focus on the influence of the changing material 113 properties (e.g. breaking strength and elastic modulus) on the development of fracture and 114 vein patterns in single and multilayered systems under loading, tectonic stretching and high 115 fluid pressures. We show that healing and vein properties play a crucial role in the dynamics 116 of the rock system. Our large temporal and spatial scale simulations demonstrate how faults 117 evolve that drain the system and how the system reaches a steady-state by accommodating 118 strain on pre-existing fractures. 


\section{The model}

Ghani et al. (2013 and 2015) proposed a numerical scheme which was built on the work of McNamara et al. (2000), Flekkøy et al. (2002), Koehn et al. (2005), Vinningland et al. (2007), Niebling et al. (2010a and 2010b) and Goren et al (2010 and 2011). Here we extend the model of Koehn et al. (2005) and Ghani et al (2013 and 2015) to study the interplay between gravitational, tectonic and fluid forces as well as healing of fractures.

The module Latte in the Elle modeling environment is being used to simulate the dynamic fracturing and healing of a pressurized sedimentary sequence (Koehn et al., 2005; Bons et al., 2008) (Fig. 2a). The basic framework for the simulations is a $2 \mathrm{D}$ hybrid triangular lattice data structure where equally sized, disk-shaped particles (nodes) are connected to their neighbors via linear elastic springs representing the discrete elastic solid (Fig. 2b). This lattice is superimposed on a stationary square grid through which the diffusion of fluid pressure takes place. The model therefore is underlain by two main computations. One deals with the linear elastic behavior of the system, whereas the other solves the porosity-dependent fluid pressure evolution.

Elastic deformation is a function of interparticle force, fluid force and gravitational force according to

$$
m_{g}\left(1+\frac{\rho_{f}}{\rho_{s}} \frac{\phi}{1-\phi}\right) \frac{d_{u_{s}}}{d_{t}}=F_{I}-\nabla P \frac{V_{g}}{1-\phi}+\rho_{e f f} V_{g} \vec{g}
$$

with $m_{g}$ being the mass of the solid element, $\rho_{f}$ and $\rho_{s}$ fluid and solid densities, $\phi$ the porosity, $u_{s}$ the velocity of the solid, $F_{I}$ forces on the solid from neighbouring solid elements, $\nabla P$ the fluid pressure gradient, $V_{g}$ the volume of the solid, $\rho_{e f f}=\rho_{s}-\rho_{f}$ the effective gravity of the solid and $\vec{g}$ acceleration due to gravity. The fluid is represented by a local fluid pressure per node and the fluid pressure evolution is calculated to follow

$$
\beta \phi \partial_{t} P^{\prime}=\nabla\left[(1+\beta P) \frac{\kappa}{\mu} \nabla P\right]-(1+\beta P) \nabla u_{s}-\beta \phi u_{s} \nabla P
$$


145 where $\beta$ is the compressiblity of the fluid, $\kappa$ the permeability of the solid and $\mu$ the viscosity

146 of the fluid. A detailed derivation of the underlying computations can be found in Ghani et al.

147 (2013 and 2015) and references therein. The solid lattice evolution is calculated using an

148 over-relaxation algorithm and the fluid pressure evolution is calculated using an Alternating

149 Direction Implicit algorithm. Both lattices are overlapped where the triangular solid lattice is

150 half the lattice size of the square fluid lattice. Values from one to the other lattice are passed

151 using a "cloud in cell" method where values are weighted with a smoothing function

152 depending on the distance between solid elements in relation to pressure nodes (Fig. 2c). The

153 solid lattice defines the porosity, permeability and local particle velocities and passes these

154 values on to the fluid pressure lattice. Porosity of the solid lattice is a function of the amount

155 of particles and thus the solid fraction in a fluid lattice cell. This porosity is converted into a 156 permeability using the Karman-Cozeny relation

$157 \quad \kappa=\frac{d^{2} \phi^{3}}{45(1-\phi)^{2}}$,

158 with $d$ the small scale grain size that is kept as a constant in the simulations. Once the 159 evolution of the fluid pressure is calculated for a given time step the fluid pressure gradients 160 are passed on to the solid particles and converted to a force that acts on single particles. This 161 force may lead to elastic deformation and fracturing once a predefined breaking threshold of 162 single bonds is overstepped. Finally broken bonds can heal again according to a healing 163 function. Healing in the model is defined by four parameters: the healing distance, the 164 healing probability, and the elastic and tensile properties of the new bonds. The healing 165 distance represents the width of the cracks. Since currently all the broken bonds enter the 166 healing function irrespective of the crack widths, they do not affect the healing time.The 167 probability gives the healing a "real" time depending on the overall time of a simulation step. 168 The healing probability $P_{\text {heal }}$ is calculated using the following Monte-Carlo approach 
$169 \quad P_{\text {heal }}=\left\{\begin{array}{r}0, \frac{l_{i, j}}{l_{\text {heal }}}<d_{i} \\ P_{0} \frac{d_{i}}{l_{i, j}}, \frac{l_{i, j}}{l_{\text {heal }}} \geq d_{i}\end{array}\right.$

170

171 with $l_{i, j}$ the distance between particle i and $\mathrm{j}, l_{\text {heal }}$ a predefined healing distance, $P_{0}$ the basic

172 healing probability and $d_{i}$ the diameter of particle $i$.

173 Fractured particles are allowed to heal with any non-connected particle that is in close

174 proximity to the healing particle irrespective of the previous connectivity of these particles.

175 Healing is done by connecting two particles with a spring that has an equilibrium length in

176 accordance to the present distance of the healing particles, so that the new spring is

177 unstressed. The new springs are then attributed with elastic and tensile constants that could be

178 different that of the unbroken bonds. The new tensile constant is the average of the breaking

179 strength of the unbroken bonds of the particle it will connect to multiplied by a predefined

180 change in the threshold. The tensile constants are characterized by normal distribution

181 similarly to the initial breaking thresholds. In addition, the local porosity of the healing 182 particles is decreased. 

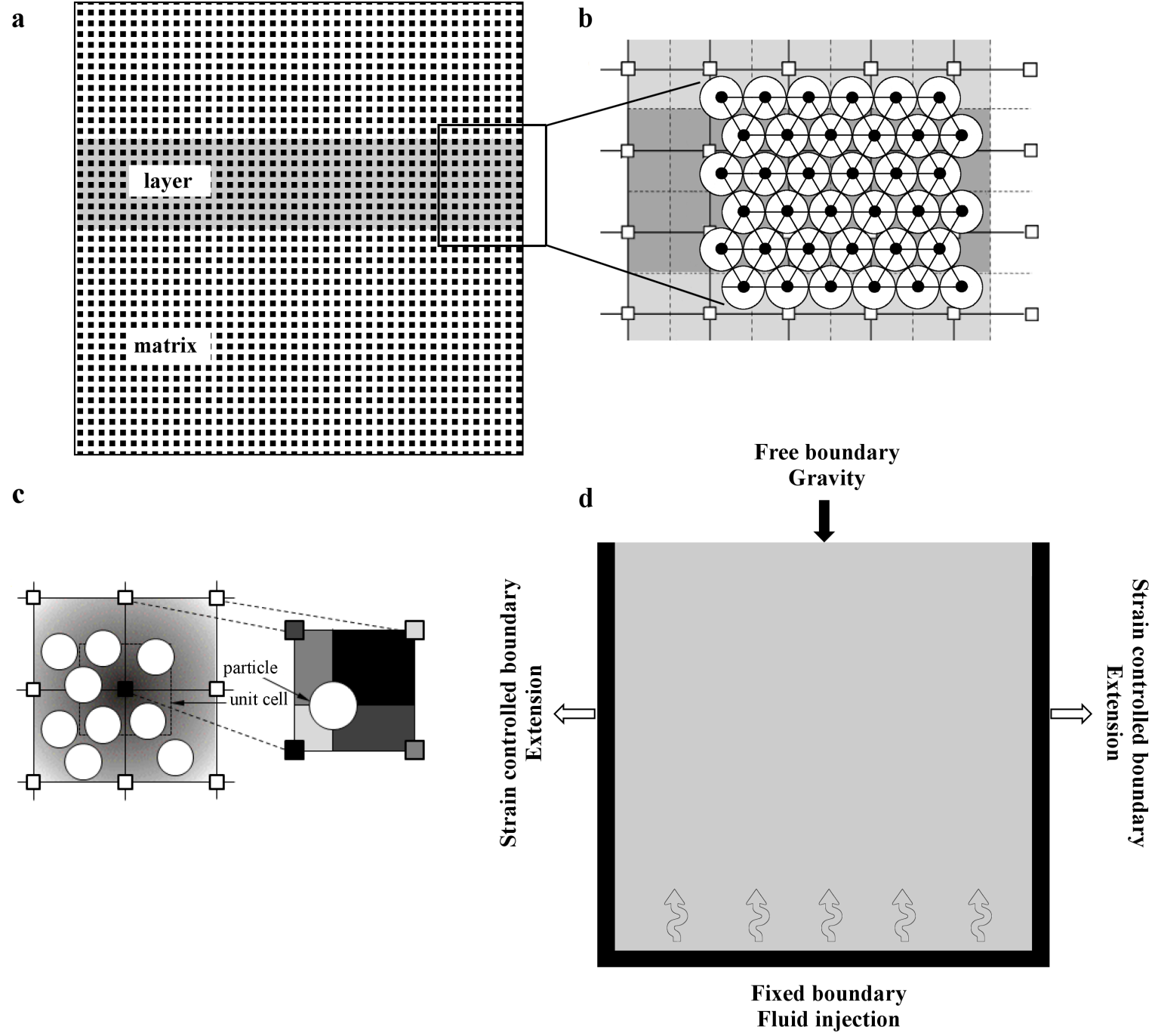

Fig. 2. Model configuration and the coupled fluid-solid interaction. (a) A stiff horizontal layer is embedded in a softer matrix. (b) The triangular DEM lattice representing the solid framework is overimposed on the continuum pressure grid. (c) Rock-fluid interaction is achieved by the smoothing function that passes information from the solid framework to the fluid based on the distance between the particles relative to the pressure nodes. (d) The deformation box is bounded by an upper free boundary through which gravity is applied; two strain controlled boundaries on the sides that are moved outwards representing tectonic extension; and a fixed lower boundary along which fluid is injected successively increasing the initially hydrostatic pressure at the bottom. 
Both the fluid lattice and the solid lattice contain several basic boundary conditions (Fig.

2d). The solid lattice has confined free-slip boundary walls on the left and right hand side as well as at the bottom of the model. These boundaries are repulsive according to linear

187 elasticity and cannot break. The upper boundary of the model is a free boundary, or a 188 boundary where vertical forces are applied according to the gravitational weight of the 189 overlying sediments. If a deformation is applied the wall on the right hand side is moved 190 outwards to model extension. In this case all particles in the model are moved according to 191 the applied deformation assuming homogeneous deformation in the model before the 192 relaxation starts.

193 In the fluid lattice the boundaries on the right and left hand side are periodic so that along 194 these no fluid can escape. The top and lower boundaries have an initially fixed pressure 195 according to a hydrostatic fluid pressure gradient in the model as a function of the depth of 196 the model and its height. Within the model the fluid pressures on the nodes are initially 197 adjusted to the upper and lower boundary condition assuming a homogeneous gradient. Fluid 198 is then mainly inserted at the bottom of the model, which is simulated as an increase in 199 pressure at given nodes.

200 In the initial setup of the simulation particles settle according to gravitational and fluid 201 forces. During successive model steps a deformation or an increase in fluid pressure are 202 applied. Fluid pressure changes are followed by the calculation of the fluid pressure evolution 203 for a time step followed by a lattice relaxation that includes the new fluid pressure gradients. 204 During a lattice relaxation particles are moved until they attain an equilibrium position. Once 205 this position is reached the model checks whether or not a bond breaks (the breaking 206 threshold is exceeded). The bond that has the highest probability to break (which is furthest 207 beyond its breaking threshold) will do so, the model is relaxed again and the model may 208 continue to break until no more bonds break. A fluid deformation step is followed by an 
external deformation that is extending the model. Following the extension the model is 210 relaxed again and can fracture. After this second fracturing event bonds can heal and the 211 model loops to the next overall time step.

212 In the presented model the simulated area, a cross section through parts of the crust, is $213200 \mathrm{~m}$ high and wide, and the model is considered to be located at $3000 \mathrm{~m}$ depth. The solid 214 has a density of $2700 \mathrm{~kg} / \mathrm{m}^{3}$. The default Young's modulus and breaking strength in the model are based on a non-dimensional coordinate system where the default values are set to 1.0 (equals $10 \mathrm{GPa}$ ) and 0.0017 (equals $17 \mathrm{MPa}$ ), respectively. The breaking strength is 217 characterized by a normal distribution between $15 \mathrm{MPa}$ and $300 \mathrm{MPa}$, which leads to a large 218 scale breaking strength of the matrix of $20 \mathrm{MPa}$. The Poisson ratio of the model is 0.33 as a 219 function of the lattice geometry. Simulations contain horizontal layers with different 220 properties to the matrix and the values are given in Table 1 and 2. One time step in the simulation corresponds to 1000 days. All the simulations run for 20000 time steps, which

222 therefore represents roughly 54.8 ka years. The extensional strain rate in the model is $10^{-14}$ $223 \mathrm{sec}^{-1}$.The fluid has a density of $1000 \mathrm{~kg} / \mathrm{m}^{3}$, a compressibility of $4.5 \times 10^{-10} \mathrm{~m}^{2} / \mathrm{N}$, a viscosity 224 of $0.001 \mathrm{~Pa}$ s and the initial porosities for the different layers are given in Table 1 and 2. The 225 healing probability of springs is set to 0.009 which means that a crack will likely close within 226 90 time steps ( $\sim 247$ years). The breaking strength and Young’s modulus of new springs may 227 be different from those of the matrix simulating strong or soft veining, the values are given in $228 \quad$ Table 1 and 2.

\section{Results}

We present six simulations with different geometries. The first four are based on a setting with one horizontally aligned stiff layer inserted in the upper half section of the model 233 to simulate a simple layered system with uniform porosities. The latter two simulations 
234 contain four horizontally aligned layers (at regular intervals) where the lowermost layers are 235 seals so that the setup represents a sealed reservoir.

236 In the first simulations we will look at the effects of healing versus no-healing mechanism.

237 This is followed by simulations that show the evolution of open fractures in a healing system.

238 We then vary the properties of the healing bonds (veins) and finally look at the behavior of 239 multilayer systems.

240

\section{3.1. Influence of healing}

242 Fig. 3 shows two simulations with identical material properties with and without healing 243 (Table 1). In both cases the deformation boxes contain a layer with an elastic modulus that is 244 eight times and a breaking strength that is twice that of the matrix. Both cases have an 245 initially hydrostatic fluid pressure gradient and the model is extended in the horizontal 246 direction with a strain rate of $10^{-14} \mathrm{sec}^{-1}$ and an increase of fluid pressure at the base of the 247 model of $\sim 31 \mathrm{MPa}$. 

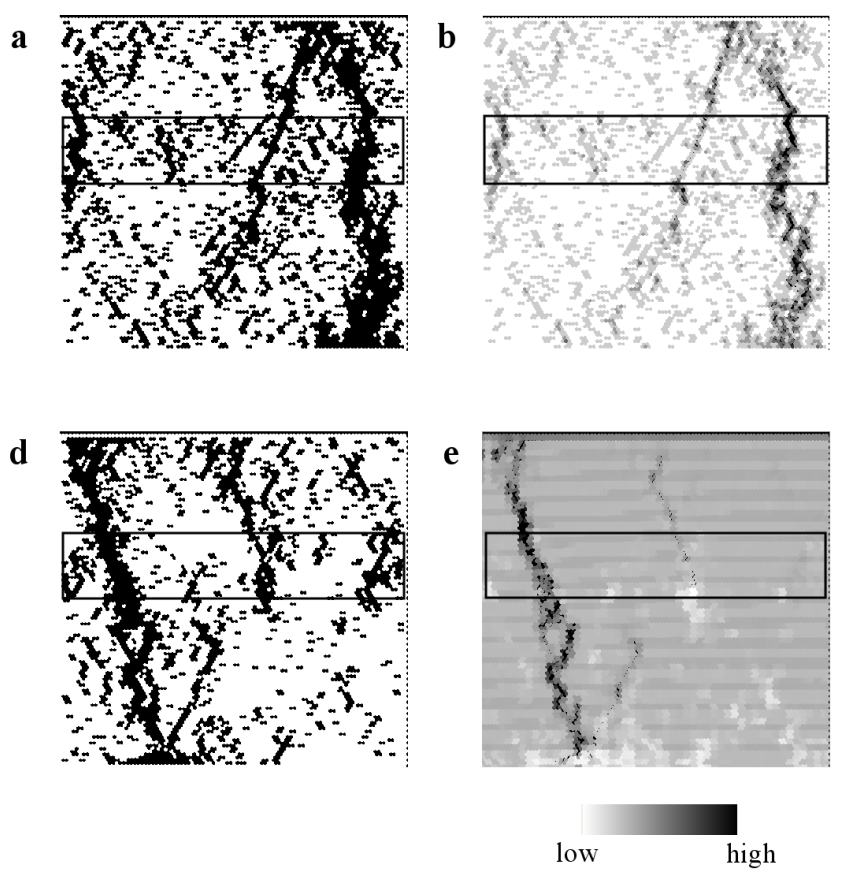
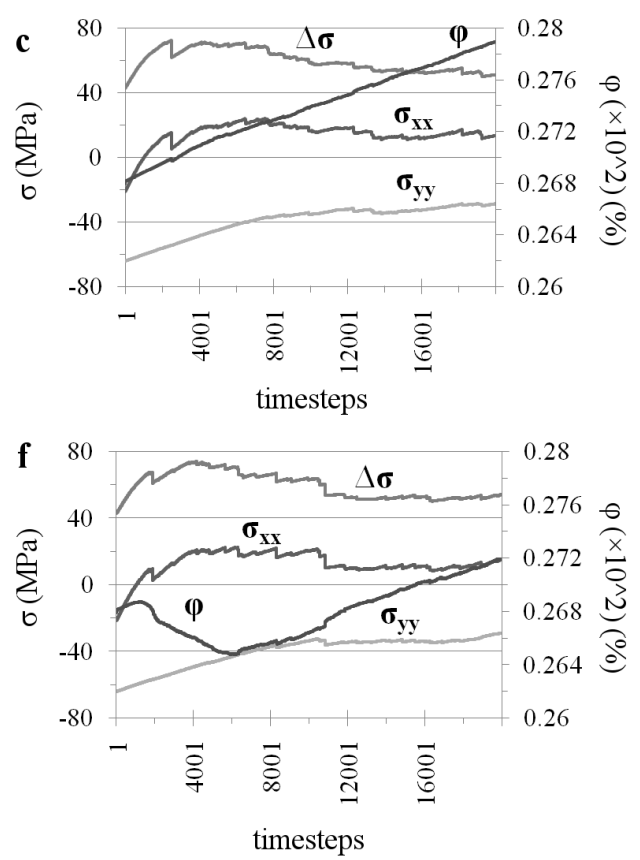

Fig. 3. Two identical simulations, one without healing (a, b, c) and one where healing is applied (d, e, f). They show the open fractures (black) (a,d), the porosity (b, e), and the stress $\left(\Delta \sigma=\right.$ differential stress, $\sigma_{\mathrm{xx}}=$ horizontal stress, $\sigma_{\mathrm{yy}}=$ vertical stress $)$ and porosity $(\varphi)$ evolution of the system (c, f) throughout 20000 time steps ( $\sim 54.8$ ka years). Black rectangle in the middle represents a stiff layer embedded in a soft matrix. Healed bonds have the same breaking strength and stiffness as the matrix. Healing has a major effect on the fracture patterns and lowers the porosity. The stress curves, however, are quite similar, whereas the porosity in the healing case first drops and only rises after 6000 time steps ( $\sim 16.4$ ka years). 
Fig. 3

Fig. 4

Fig. 5

Fig. 6

\begin{tabular}{lc|cccc}
\hline Matrix & $\mathbf{E}(\mathbf{G P a})$ & 7.5 & 7.5 & 7.5 & 7.5 \\
& $\boldsymbol{\sigma}_{\mathbf{u}}(\mathbf{M P a})$ & 20 & 20 & 20 & 20 \\
& $\boldsymbol{\varphi}(\mathbf{\%})$ & 26.9 & 26.9 & 26.9 & 26.9 \\
\hline Layer & $\mathbf{E}(\mathbf{G P a})$ & 60 & 60 & 60 & 60 \\
& $\boldsymbol{\sigma}_{\mathbf{u}}(\mathbf{M P a})$ & 40 & 20 & 20 & 20 \\
& $\boldsymbol{\varphi}(\mathbf{\%})$ & 26.9 & 26.9 & 26.9 & 26.9 \\
\hline $\begin{array}{l}\text { Healed } \\
\text { bonds }\end{array}$ & $\mathbf{E}(\mathbf{G P a})$ & 7.5 & 15 & 7.5 & $2.25 ; 5.63 ; 17 ;$ \\
& & & & 8 & $37.5 ; 75$ \\
& \multirow{2}{*}{20} & 20 & 20 & 20 \\
& & & & 200 & \\
& & & & &
\end{tabular}

251 Table 1. Real scale properties for simulations shown on Fig.3 to Fig. 6. E = elastic modulus, $252 \sigma_{\mathrm{u}}=$ breaking strength, $\varphi=$ porosity. The default overall breaking strength is $20 \mathrm{MPa}$, which 253 represents the central value of the threshold. 
255 In the case without healing (Fig. 3a, b, c) a considerable amount of open fractures can be seen 256 that are directly linked to higher porosity values. The porosities are uniformly low in places 257 that are not fractured. The major fracture that cuts through the entire system shows the 258 highest porosities due to constant refracturing. The porosity evolution (Fig. 3c) shows that 259 without healing the porosity increases almost linearly with progressive deformation from the 260 initial $26.9 \%$ to almost $27.8 \%$. This effect is due to the extension of the system in the 261 horizontal direction that increases the overall porosity linearly.

262 Healing has an effect on the number of open fractures (Fig. 3d, e, f). In comparison to the 263 non-healing case the healing system has less open fractures. The overall fracture pattern with 264 and without healing is similar. In both cases a large through-going fracture develops that 265 opens the system and has the highest porosity. However, the healing case shows fewer 266 fractures in the stiff layer and in the matrix away from the major fractures. This implies that 267 local fractures are closed whereas the large ones are continuously reopening. The porosity 268 evolution of the healed case also differs from the non-healing simulation. The porosity first 269 declines and only starts to rise after time step 6000 ( $\sim 16.4$ ka years), which in turn results in 270 overall porosity increase of the system (from $26.9 \%$ to $27.2 \%$ ). The reason for the initial 271 porosity decrease is induced by the healing of fractures that works against the extension of 272 the system. Once the deformation localizes in the large through-going system these are 273 continuously opening and opposing the healing so that porosity increases again.

274 Both simulations show identical stress evolution (Fig. 3c, f). As deformation is applied stress 275 builds up and reaches a maximum value after which the system relaxes due to major 276 fracturing and only minor fluctuations (slip/fracturing along existing fractures and minor 277 fracturing in the matrix) can be observed. The horizontal stress $\sigma_{\mathrm{xx}}$ quickly moves from 278 compressional to the tensional regime around time step $1000(\sim 2.8$ ka years $)$ and experiences 279 its highest magnitude during time step $4000-6000$ ( 11 ka - 16.4 ka years). This is a 
function of the extension in the horizontal direction that leads to extensional failure. The vertical stress $\sigma_{\mathrm{yy}}$ on the other hand stays in the compressional regime during the entire simulation because of the gravitational load. Drops in differential stress illustrate failure in

283 the system. After about 12000 time steps ( 32.8 ka years) in both simulations the stresses

284 reach semi-constant values implying that it reaches a statistically stationary state, where

285 existing fractures take up most of the strain. The stress curve of the healing case shows a 286 pronounced stress drop after time step 10000 ( 27.4 ka years) which cannot be seen in the non-healing case. In this case the healing is influencing the failure process leading to healing of fractures that have to be fractured again.

289

290

291

292

\subsection{Fracture evolution}

Fig. 4 shows the time evolution of open fractures in a simulation with healing. In this case the competent layer's elastic modulus is eight times that of the matrix and the healed bonds' elastic moduli are twice those of the matrix (Table 1). Larger tensile stresses develop at lower strain in the layer due to its high stiffness, therefore it fractures first and only small amount of fracturing can be seen in the matrix. Fractures propagate by interconnections of smaller cracks. After time step 1900 ( $\sim 5.2$ ka years) the first bed-confined fractures propagate into the matrix. The matrix, however, is too soft for these fractures to propagate further until time step 5700 ( 15.6 ka years $)$ when there is significant deformation in the matrix as well. After this stage fracturing in the layer is subordinate, whereas fracture propagation in the matrix is becoming the dominant process. Except for the formation of the large fracture zone along the left boundary, fracturing is limited after time step 9500 ( 26 ka years) which indicates that the system is approaching a somewhat steady-state. Fracture spacing decreases with the elastic constant of the layer and therefore spacing is much tighter in the competent

304 layer than it is in the less competent matrix. 

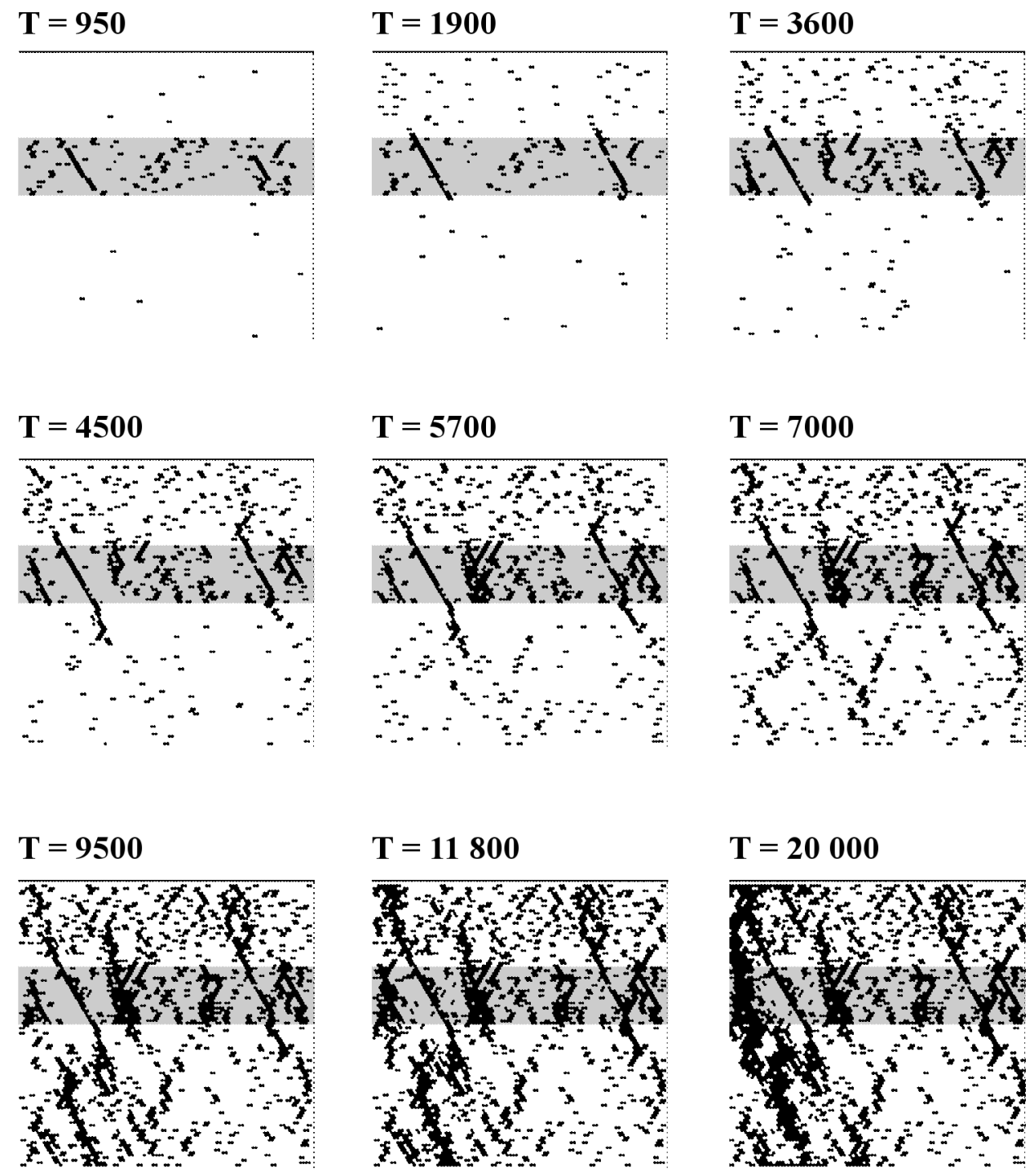

Fig. 4. Evolution of open fractures (black) throughout 20000 time steps ( $\sim 54.8$ ka years) when healing is applied. $\mathrm{T}$ is the model time, whereas the shaded grey rectangle in the middle represents a stiff layer embedded in a softer matrix. Healed bonds have the same breaking strength and stiffness as the matrix. First fractures form in the layer and these propagate into the matrix by linking up smaller cracks. Towards the end of the simulation strain seems to be accommodated by existing fractures and only a limited amount of new fractures form. A through-going fault develops at the end providing connection between the lower and the upper end of the system. 


\subsection{Importance of breaking strength and elastic modulus of the healed bonds}

The influence of the breaking strength of the healed bonds was investigated by varying only this parameter in the same simulation setup (Table 1). Three cases are presented in Fig.

3105 ; one where the breaking strength of the veins is a quarter of the matrix, one where it is the 311 same and one where it is ten times the matrix. Fig. 5 shows the fracture age of active fractures 312 (Fig. 5a), the healing age of actively healed bonds (Fig. 5b), fractures that have healed and 313 refractured several times (crack-seal veins) (Fig. 5c), the porosity of the solid (Fig. 5d), and

314 the stress and porosity evolution over 20000 time steps for the three cases (Fig. 5e).

315 A variation of the breaking strength of healing bonds changes the behavior and fracture

316 pattern of the model significantly. Fig. 5a shows that number of open fracture decrease with 317 the strength of the bonds. This is especially pronounced in the case where the veins are 318 stronger than the matrix so that only one large open fracture remains. In addition, Fig. 5a 319 shows that many older fractures (i.e. those that formed at earlier time steps) are still open 320 when veins are weak, whereas most of these are closed when the veins are strong. In all three 321 cases the formation of new fractures is localized along the through-going large scale fractures or the faults that develop at the end of the simulations.

323 The healing patterns shown in Fig. $5 \mathrm{~b}$ reflect a change from a moderately healed system with 324 soft veins to a system which is basically clogged up when the veins are strong. When the new 325 bonds are weaker, the oldest veins appear mainly above and in the layer and subordinately in 326 the matrix. Veins are progressively getting younger towards the bottom. When the new bonds 327 are the strongest the older veins still appear mainly in the layer but as the entire system is constantly healing it is difficult to observe any preferred locations of the younger veins. The youngest veins, however, seem to be associated with the fault. 
a

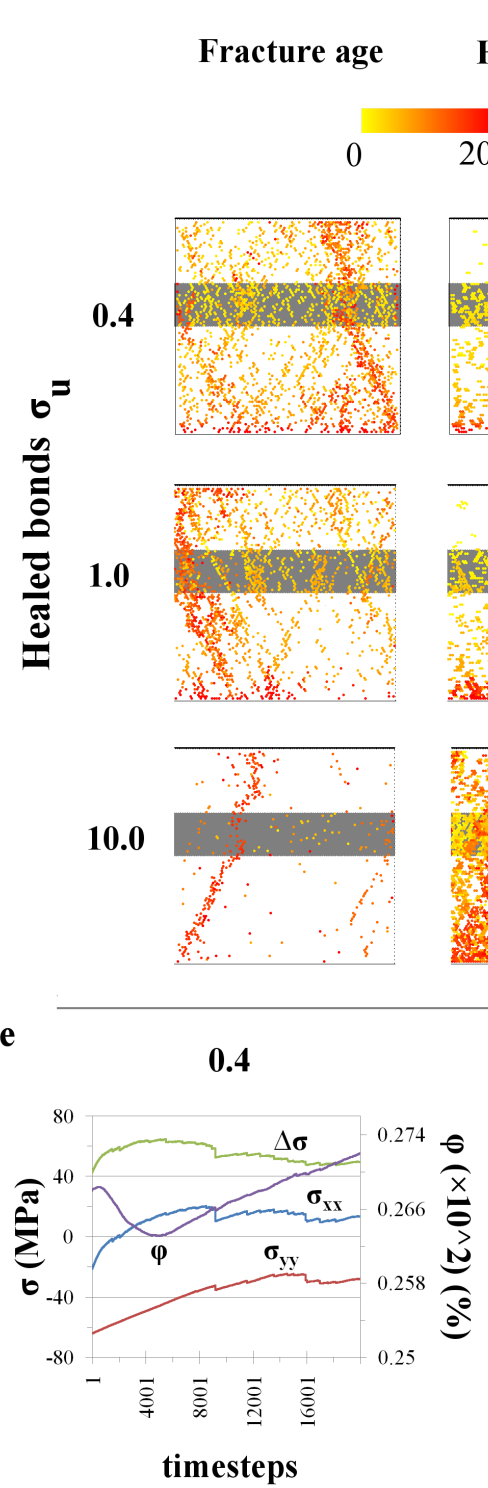

b

Healing age

20000 ts
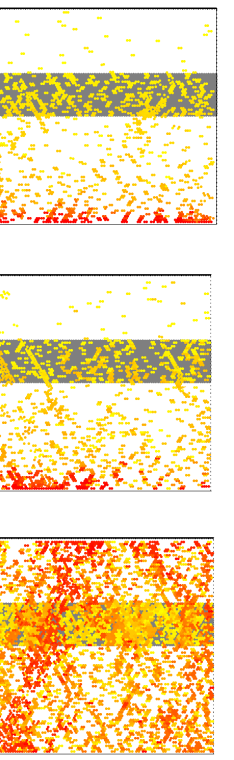

c d

Porosity

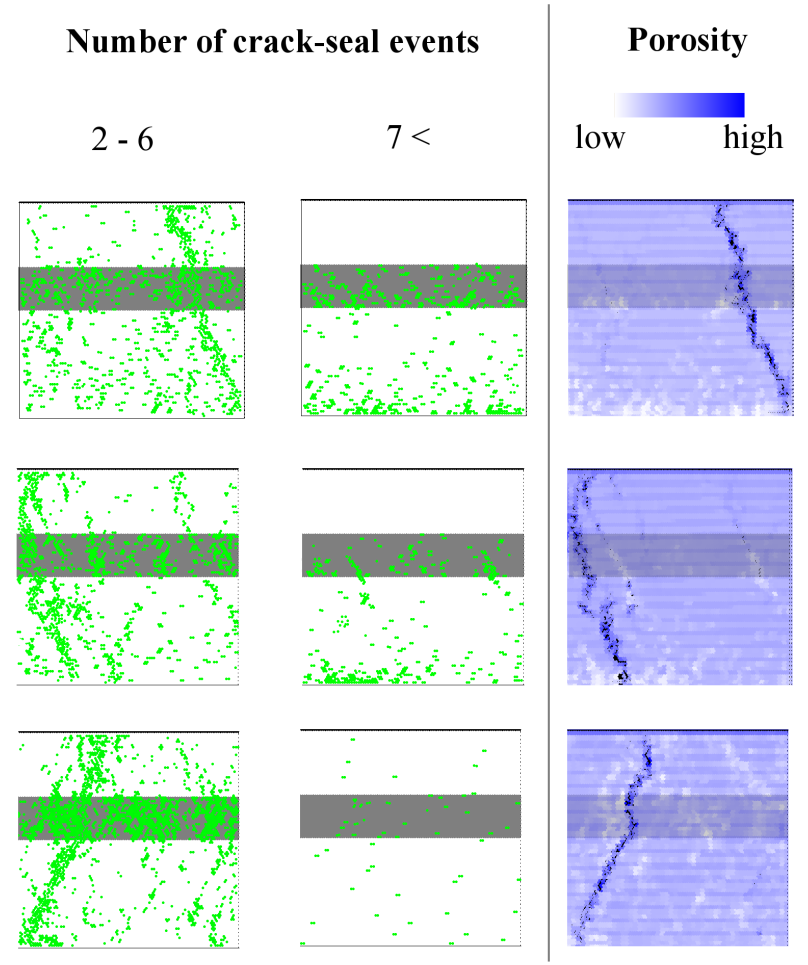

1.0

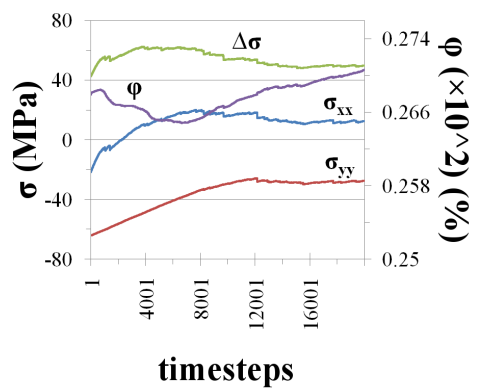

10.0

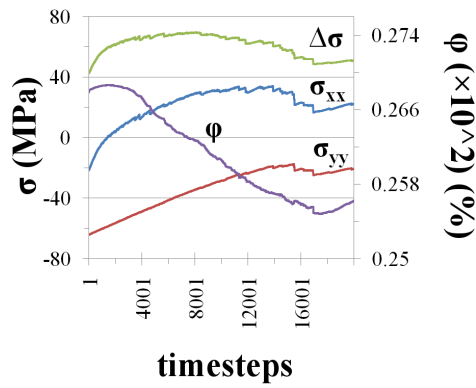

Fig. 5. Three simulations involving different vein strength, one where the breaking strength $\left(\sigma_{u}\right)$ of the healed bonds are quarter of the matrix (0.4), one where they are the same (1.0), and one where they are ten times the matrix (10.0). Shaded grey rectangle represents a stiff layer embedded in a softer matrix. We can examine the effects of the veins' strength on the evolving fracture (a) and healing patterns (b), crack-seal cycles (c) and porosity (d). The age of the fracturing and healing is also shown, indicating that in all cases new fractures are localized at the through-going faults, whereas the new veins form at different locations. When the veins are relatively weak, the bottom of the box and layer heal intensely, whereas when they are strong, the new veins are more localized close to the open fractures. Generally, the stronger the veins, the less open fractures are present and the more intense the healing is. In case the veins are strong, the system at each healing event becomes progressively stronger, thus undergoes less crack-seal cycles. The corresponding stress $\left(\Delta \sigma=\right.$ differential stress, $\sigma_{\mathrm{xx}}=$ horizontal stress, $\sigma_{\mathrm{yy}}=$ vertical stress) and porosity $(\varphi)$ evolution is therefore entirely different (e). Stresses are elevated and the porosity drops significantly when the veins are strong. In all cases, however, the system tends to reach a steady-state represented by a relatively constant stress state with only small fluctuations. 
332 The number of crack-seal events is illustrated in Fig. 5d. The breaking strength of the healed

333 fractures determines the localization of the refracturing and healing process.

334 When the veins are weaker than the matrix, they tend to fracture easily. This is reflected in 335 the similarity of the healing and the crack-seal $(7<)$ pattern for the weak vein simulation

336 (Figs. 5a and 5c), which implies that after the bonds heal they will constantly fail and heal

337 again. Locations that experienced less crack-seal events (2-6) coincide mainly with the 338 younger open fractures.

339 Slightly different behavior can be seen when the veins have the same strength as the matrix.

340 Fewer veins undergo more than seven crack-seal events, whereas most of the veins and

341 fractures only experience limited crack-sealing (2-6 events).

342 However, when the breaking strength of the veins is ten times that of the matrix, most of the

343 bonds only fracture and heal once (see the older veins in the background in Fig. 5b). As

344 healing now makes the entire system progressively stronger initiation of new fractures is

345 impeded. Even if veins refracture, the refracturing itself seems to be restricted to the layer and

346 to a few bigger fracture zones. Only a limited amount of locations experience more than 7

347 crack-seal events.

348 Relative porosities in all cases seem to have similar characteristics (Fig. 5d). Large through-

349 going faults are associated with the highest porosities, whereas healed fractures decrease the 350 local porosities.

351 Fig. 5e shows stress and porosity curves that illustrate how the behavior of the

352 systems changes with increasing vein strength. In the first case when the veins are a quarter

353 of the matrix's strength the vertical stress component $\left(\sigma_{\mathrm{yy}}\right)$ linearly increases until time step

3549000 ( 24.6 ka years $)$ after which the increase is less intense and $\sigma_{\text {yy }}$ fluctuates around a

355 mean value. In the early stages of deformation the slope of horizontal stress component $\left(\sigma_{\mathrm{xx}}\right)$

356 is steeper than the vertical component $\left(\sigma_{\mathrm{yy}}\right)$ but it progressively flattens out as smaller shear 
fractures form. A pronounced stress drop at time step 9000 ( 24.6 ka years) marks a sudden failure of the system which relaxes stresses afterwards. The porosity $(\varphi)$ shows a sudden drop to the value of $26.45 \%$ at the beginning of the simulation which is then followed by a porosity-increase towards the end of the simulation reaching a value of $27.2 \%$. The point where the porosity begins to rise coincides with the maximum differential stress $(\Delta \sigma)$.

362 The stress and porosity evolution is quite similar when the veins are the same strength as the matrix. The only difference is that the porosity reaches its minimum at $26.6 \%$ and its maximum at $27.4 \%$.

When the veins are the strongest the horizontal stress $\left(\sigma_{\mathrm{xx}}\right)$ and the vertical stress $\left(\sigma_{\mathrm{yy}}\right)$ magnitudes are much higher than they were in the weaker cases. As the system is becoming successively stronger during healing elevated stresses are expected. Stress curves suggest that the stress build-up is prolonged and a quasi steady-state regime, when the stresses show only minor fluctuations, is reached at a later stage of the deformation than in the other two cases.

370 Similarly to the weaker cases the system experiences its maximum differential stress $(\Delta \sigma)$ at

371 earlier stages (around time step $7000(\sim 19.1$ ka years)) but the porosity continuously

372 decreases until time step 17000 ( $\sim 6.5$ ka years) and reaches its minimum $25.6 \%$ close to the 373 end of the simulation. These delayed behaviors can be explained with the system being too strong to fracture efficiently and also with pronounced veining throughout the system in the stronger vein case. Veining with a porosity decrease works against extensional deformation

376 with a porosity increase in all simulations. Since veining is much more pronounced in the 377 matrix in the strong vein case the porosity increase due to deformation takes place at a later 378 stage. This stage also marks a switch from strain taken up by fracturing to strain being taken 379 up by opening of larger scale fractures or faults. In the next set of simulations we focus on the effect of a variation of the Young's

381 modulus of veins on the behavior of the system. Five simulations were performed where the 
382 breaking strength of the veins were the same as the matrix and only the Young's modulus of 383 the healed bonds varied between a third to ten times the stiffness of the initial bonds (Table

384 1). Fig. 6 shows that more open fractures are present when the veins become stiffer. This is 385 coupled with the healing pattern. An increase of the number of open fractures is reflecting a 386 decrease in healing. The most pronounced case is the first where the veins are too soft to 387 refracture in the lower parts of the model. An increase in Young's modulus and a decrease in 388 breaking strength can have similar effects. This is seen best in the case where the Young's 389 modulus is low and where the breaking strength is high. In both cases the amount of open 390 fractures decreases. However, the overall effect on the elastic properties of the system are 391 opposite, a soft vein makes the system soft and reduces stresses whereas a vein with a high 392 breaking strength makes the system strong and thus leads to a stress increase. Overall the 393 breaking strength seems to have the most pronounced effects on the pattern forming, 394 probably because with increasing strength, the amount of open fractures decreases, the 395 system heals strongly and the stress increases. 


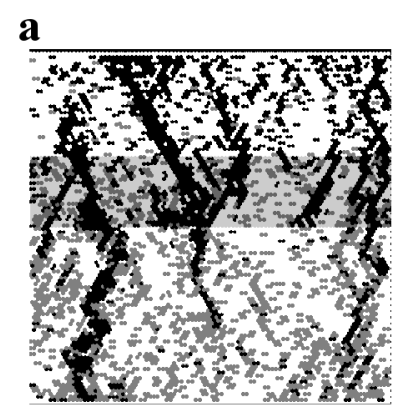

\section{d}

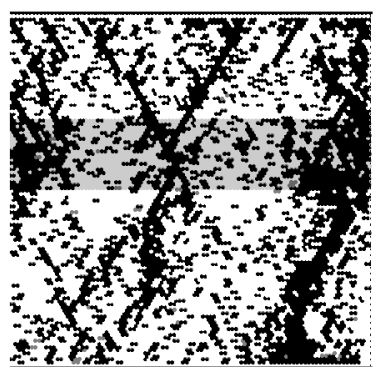

b

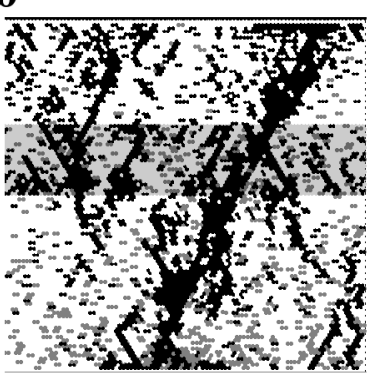

c

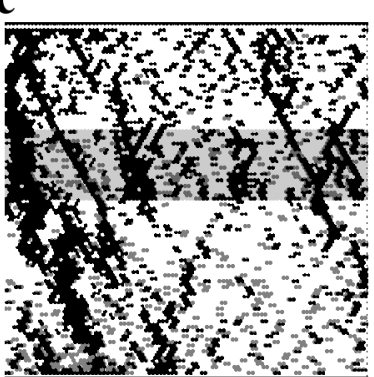

400

Fig. 6. Open fractures (black) and healed bonds (medium grey) are shown when the ratio of the veins' elastic moduli over the matrix one is $1 / 3$ (a), $3 / 4$ (b), 1 (same as the matrix) (c), 5 (d) and 10 (e). Shaded light grey rectangle represents a stiff layer embedded in a softer matrix. All simulations show the patterns after 20000 time steps ( 54.8 ka years). As opposed to the soft veins, stiff veins tend to refracture affecting the fracture geometries. The effect of the elastic modulus, especially in the (c), (d) and (e) case, is not that significant considering the large magnitude change and comparing the results to the simulations exploring different values of breaking strength shown on Fig.5.

3.4. Seals and fluid pressure gradients in multilayered systems

In the following simulations we add seals at the bottom of the system in order to study

404 the interplay between fluid and deformation. Multilayered seal reservoirs are quite common

in nature where areas with higher porosities are vertically sealed off by horizontally aligned

low-permeability layers. In the simulations fluid is added at the bottom so that fluid pressure

gradients build up across the lowermost seal where the fluid cannot escape vertically. In these

simulations we introduce four layers out of which the lowermost is a seal with $0.51 \%$

simulations. The simulation in Fig. 7a has layers that are all more competent than the matrix

411 (Young's modulus is eight times higher than the matrix), whereas the simulation shown in 
412 Fig. 7b has a seal layer (lowermost layer, above the bottom one) that is less competent than

413 the matrix (Young's modulus is one third of that of the matrix).
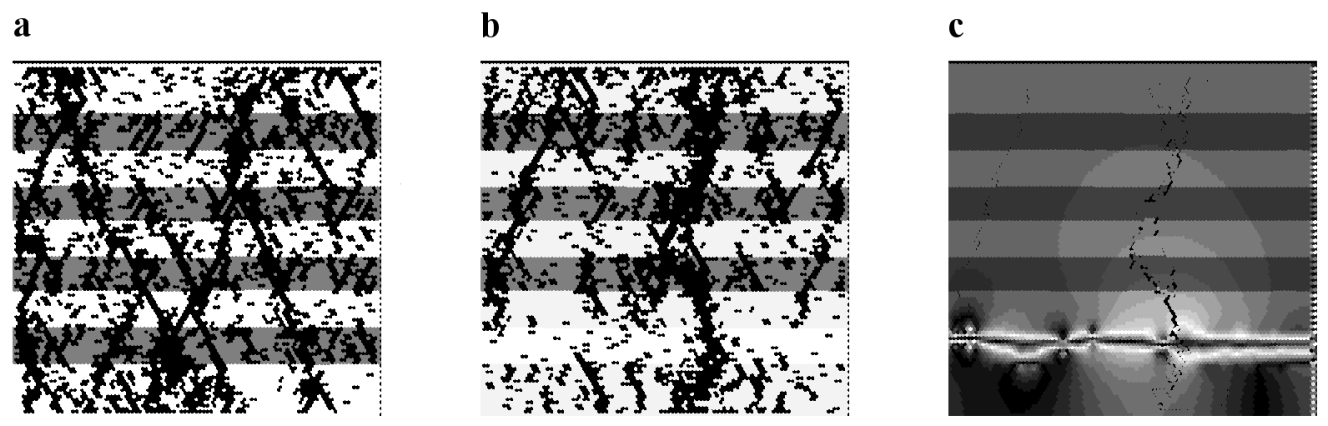

Fig. 7. Multilayered simulations after 20000 time steps ( $\sim 54.8$ ka years). Dark grey shaded rectangles represent stiff layers, whereas the white one is a soft layer. In simulations (a) and (b) the lower layers (just above the bottom one) are seals with porosities of $0.51 \%$. The other layers have background porosity $26.9 \%$. The seal seems to be only effective when it is soft as fracturing is limited within them - as in (b), compared to (a). Correspondingly, large fluid pressure gradients evolve within the seal and smaller gradients seem to intrude along the larger fractures and through-going fault possibly indicating drainage: (c) indicates the fluid pressure in simulation (b).

Fig. $7 \mathbf{a}$

\begin{tabular}{ll|cc|}
\hline Matrix & $\mathbf{E}(\mathbf{G P a})$ & 7.5 & 7.5 \\
& $\boldsymbol{\sigma}_{\mathbf{u}}(\mathbf{M P a})$ & 20 & 20 \\
& $\boldsymbol{\varphi}(\mathbf{\%})$ & 26.9 & 26.9 \\
\hline Bottom layer & $\mathbf{E}(\mathbf{G P a})$ & 60 & 2.25 \\
& $\boldsymbol{\sigma}_{\mathbf{u}}(\mathbf{M P a})$ & 20 & 20 \\
& $\boldsymbol{\varphi}(\mathbf{\%})$ & 0.51 & 0.51 \\
\hline Other layers & $\mathbf{E}(\mathbf{G P a})$ & 60 & 60 \\
& $\boldsymbol{\sigma}_{\mathbf{u}}(\mathbf{M P a})$ & 20 & 20 \\
& $\boldsymbol{\varphi}(\mathbf{\%})$ & 26.9 & 26.9 \\
\hline Healed bonds & $\mathbf{E}(\mathbf{G P a})$ & 7.5 & 7.5 \\
& $\boldsymbol{\sigma}_{\mathbf{u}}(\mathbf{M P a})$ & 20 & 20 \\
\cline { 3 - 4 } & & &
\end{tabular}

415 Table 2. Real scale properties for simulations shown on Fig. 7. $\mathrm{E}=$ elastic modulus, $\sigma_{\mathrm{u}}=$ 416 breaking strength, $\varphi=$ porosity.

417 When the seal is competent (Fig. 7a) it does not seem to have a great effect on the fracture

418 patterns since the layers and the matrix fracture similarly throughout the entire system with

419 the competent beds containing a higher amount of fractures with closer spacing compared to

420 the matrix. The beds interact with each other by connecting closely-spaced layer-confined 
421 fractures. These then evolve to large through-going faults that not only localize crack-sealing,

422 but also provide direct communication between the lower and upper parts of the system. The

423 Young's modulus localizes deformation that is mainly controlled by the extension on the

424 system. The system is drained relatively early through large fractures or faults so that the

425 influence of the seal is not very high. Fluid pressure build-up leads to increased fracturing in

426 the lowermost parts of the matrix below the seal.

427 The same simulation was performed with a soft seal in order to inhibit seal breaking and

428 thus stimulating fluid pressure build-up. This scenario does seem to have a greater effect on

429 the developing patterns (Fig. 7b). The seal acts like a stress barrier that hampers fluid

430 pressure gradients to transfer through the seal, thus inhibiting fracture initiation. The

431 lowermost part of the matrix around the soft seal is now building up less stress than the three uppermost competent layers. The fracture pattern in the competent beds and surrounding matrix looks similar to the scenario shown in Fig. 7a, but the lower part of the model is too

434 soft to initiate significant fracturing. However, fracturing is still pronounced below the seal

435 where the fluid pressure builds up. Fractures are almost non-existent in the seal.

436 Only at the end of the simulation a large fracture or fault develops linking layers above the 437 seal with layers below the seal allowing fluid pressures to decrease. This large fracture or 438 fault leads to seal breaking and drainage of the system. The simulations show that competent 439 seals are not very effective since they build up high stresses easily leading to failure. This is 440 especially true during layer parallel extension. Soft seals shield stresses and are thus very

441 effective in building up fluid pressures below the seal. One possible scenario of seal failure is 442 the development of large scale faults that run through the whole system and thus are also 443 fracturing the seal.

444 Seal leakage is illustrated in Fig. 7c, where the fluid pressure is displayed as a graymap.

445 When the fluid pressure gradient is larger, isobars are closer to each other, and such region 
446 corresponds to apparent fringes on Fig 7c. The seal experiences the largest fluid pressure

447 gradients. The fringes along the through-going fault indicate drainage as fluid flows in from

448 below along the high permeability fault. These gradients might weaken the fault plane since

449 they are aligned radially along the fault so that a fault-parallel gradient (and thus a fault-

450 extending fluid force) is also present (Zoback and Harjes, 1997).

451

452

4. Discussion

453

In our simulations, regardless of the vein properties, healing decreases the local porosity

454 and mainly affects the small scattered fractures. This is a result of the implemented healing as

455 currently the healing probability is a function of the distance between particles, which causes

456 smaller cracks to heal faster. The fracture patterns are also strongly influenced by the

457 heterogeneous stress field created by gravity, tectonic stretching and fluid pressure gradients.

458 This is consistent with the findings of Ghani et al. (2013 and 2015) who also pointed out that

459 unless the fractures are formed exclusively by fluid pressure gradients, they will not look

460 fundamentally different to purely tectonic ones. Consequently a range of different fracture

461 sets can develop due to the interplay between the applied driving forces. Fractures that

462 develop are a combination between mode I extensional and mode II shear fractures, which

463 was also observed by Ghani et al. (2013).

464 The deformation is strongly controlled by the competent layers in the system as their

465 fragmentation defines propagation and the localization of faults. In accordance with earlier

466 research the fractures in the model saturate (Becker and Gross, 1996; Bai and Pollard, 2000;

467 Gross and Eyal, 2007). According to Tang et al. (2008), saturation of fracturing is reached

468 either by fracture formation, strain accommodation or stress shadows. This is nicely

469 illustrated in Fig. 3 in the stress plots where fracturing first leads to a decrease in stress until

470 the fractures are saturated and is followed by strain being localized along the developing 
471 larger fractures or faults that open. This saturation is accompanied by a quasi steady-state

472 stress in the plots where the stresses remain constant with only minor fluctuations. Healing

473 does change this saturation behavior somewhat, so that the stress-drop due to fracturing and

474 thus the development of a steady state scenario happening at a later stage. One can also argue

475 that the saturation takes place in two stages because of the competent layer in the system. Fig.

4764 shows how the layer-confined fractures start to propagate into the matrix only after fracture

477 initiation in the bed becomes subordinate or even ceases. This first stage could correspond to

478 the described saturated levels of the layer, showing fracture saturation on a local scale. Later

479 on the entire system also reaches saturation as shown in the steady-state stresses where

480 additional strain is accommodated by opening or slip along pre-existing fractures (Koehn et

481 al., 2005). As discussed above this saturation is reached even if the system is healing. It has

482 been previously argued that if the cataclasite in a fault heals and gains certain strength, it

483 might fail catastrophically at high stresses (Scholz, 2002; Koehn et al., 2005). Our results do

484 not support this concept in the presented simulations. There can be several explanations for

485 this difference. First of all in our model high fluid pressure gradients are constantly applied

486 and are keeping the evolving faults open through which draining of the system is possible. As

487 opposed to this, in nature a possible scenario could be that after the fault heals the fluid

488 source that produced the high pressure gradients exhausts and stresses relax so that there is no

489 major deformation. If there is a sudden increase in stresses for instance either due to an

490 earthquake or high pressure fluid, the healed fault could indeed fail catastrophically. In

491 addition, the velocity of the healing will affect the system. If the system heals very fast it may

492 seal a potential fault very fast leading to the build-up of new stresses and failure of the fault.

493 As was illustrated above, the breaking strength of the healed bonds also affect the system. If

494 the healing is fast and makes the fault very strong then the stresses that are needed to

495 reactivate the fault are increasing and fracturing may become more catastrophic. 
The elastic modulus is considered as an important factor in fracture evolution by

497 Simonson et al. (1978), whereas Smith et al. (2001) and McDermott et al (2013) argue that its

498 importance in strata-bound systems is overrated. Our simulations show that the elastic

499 modulus of the veins seems to influence the fracture patterns. The stiffer the veins, the more

500 fractures are open (Fig. 8b, d). This is expected as the stiff veins develop higher stresses and

501 thus fracture more easily, whereas the soft veins need larger strains to refracture. This means

502 that the stiffer veins undergo more crack-seal events than the soft ones, and therefore might

503 provide more efficient paths for fluid flow. However, the elastic modulus seems to play an

504 increasing role in combination with other mechanical properties (Fig. 8). Together with the

505 vein's strength it produces strong localization of crack-seal events in the layer when the veins

506 are ten times stronger than the matrix. In the multilayered system, on the other hand, the

507 seal's effectiveness is influenced by the elastic modulus. The stiff seal fails during

508 deformation decreasing pressure gradients and contributing to flow channelization across the

509 seal. Soft seals, on the other hand, suppress fracturing within and thus behave as a stress

510 barrier that controls the fracture evolution and the fluid flow. These combined effects of

511 different mechanical parameters in fact demonstrate how one cannot single out properties or

512 at least should be cautious when it comes to understanding the behavior of a system. 
$\mathbf{a}$

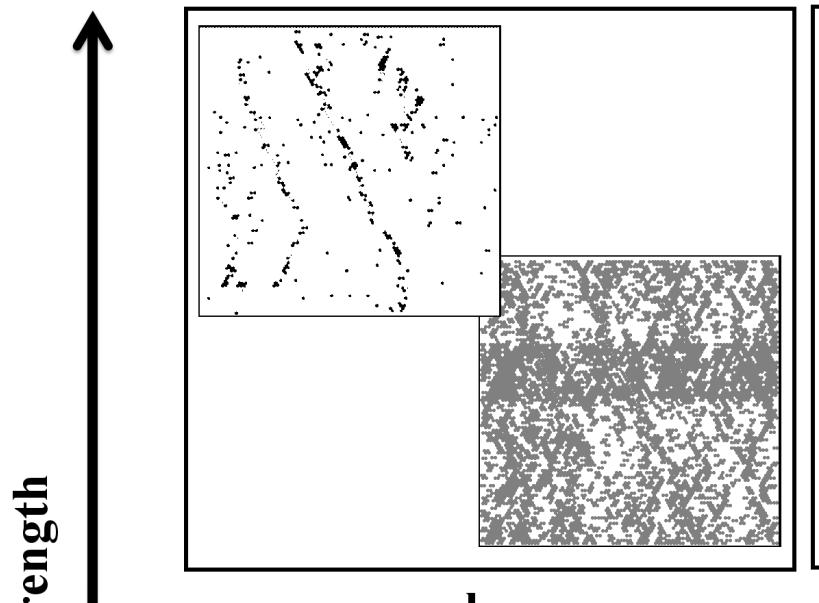

b

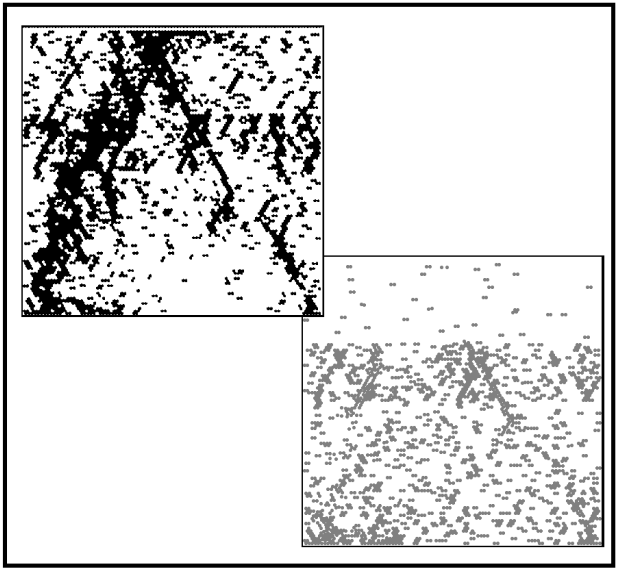

c

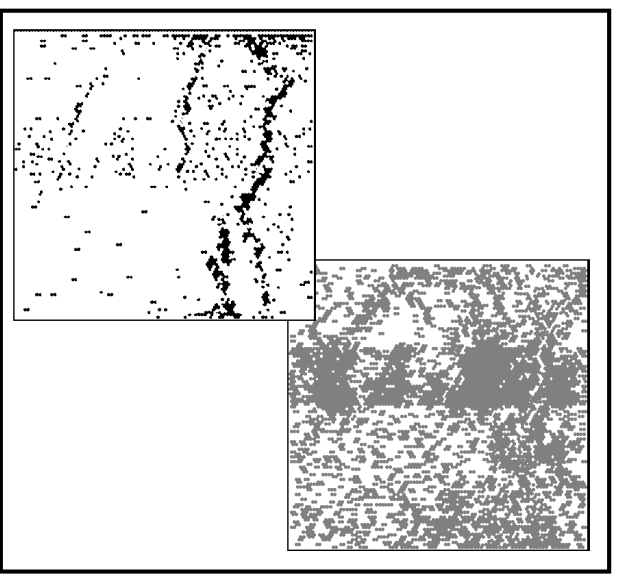

d

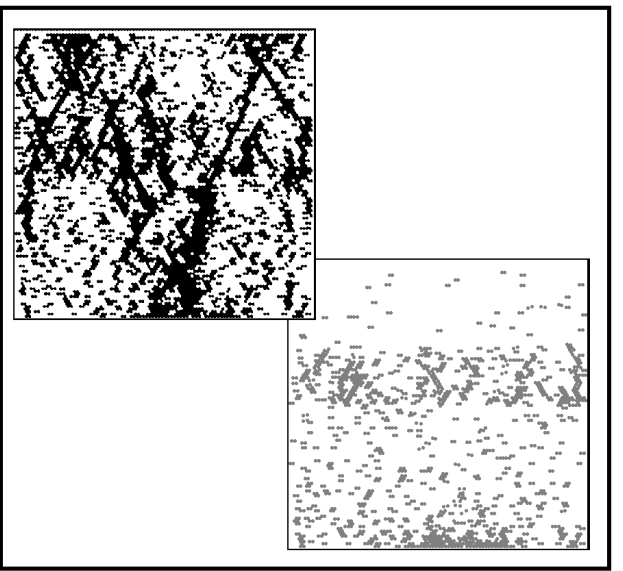

\section{vein stiffness}

Fig. 8. Developing fracture (black) and vein (grey) patterns as a function of vein stiffness and strength. The four cases show (a) strong veins that are soft, (b) weak veins that are soft, (c) strong veins that are stiff, and (d) weak veins that are stiff. An increase in stiffness does not influence the evolving patterns as much as an increase in strength. Simulations represent 20000 time steps ( $\sim 54.8$ ka years) and a stiff layer is embedded in a softer matrix as shown on Fig. 2 a.

515 The breaking strength of the veins seems to have a greater influence on the evolving patterns

516 than the elastic modulus (Fig. 8). This implies that it is very important in a natural system to

517 understand the breaking strength of veins. The veins breaking strength depends on the

518 different mineral assemblages within the vein but also on the vein-wallrock contact. Calcite,

519 especially combined with other soft minerals such as gypsum, makes the veins weak, whereas

520 quartz or ore minerals particularly strengthen the veins. One example for a system where the 
521 new veins or healed bonds have a very high breaking strength could correspond to the

522 development of ore bodies. Strong veins undergo less crack-seal cycles, leading to an overall

523 healing of the system (development of ore bodies) and to the development of only very

524 limited amount of mainly large-scale open fractures or faults forming fluid conduits to feed

525 the system. Natural veins therefore could potentially indicate strong mechanical influence on

526 the deformation history and permeability evolution (Fig. 1).

527 The porosity evolution in the system without healing is straightforward, the porosity

528 increases because of the extension on the system. Once healing is involved the porosity

529 evolution becomes more complex with an initial decrease that is a function of the healing.

530 Healing reduces the porosity in the system until strain localizes in larger scale fractures or

531 faults that open enough to overcome the healing so that porosity increases again linearly as a

532 function of extension on the system.

533 The shown simulations correspond to approximately 54.8 ka years meaning that our results

534 assume that the deformation path is constant throughout this period, which might not be the

535 case. It is therefore worth to note that an interruption in the deformation and re-application of

536 previously occurred stresses might produce different geometries (Mahrer, 1999).

537 Our future work with the presented code will include improving the porosity function,

538 involving compression and tilted layers, and tracing the fluid through the porous media to

539 detect the fluid flow throughout the entire simulation.

540

541 5. Conclusions

542 We present a hydrofracture model that incorporates the intimate coupling of the elastic

543 framework (solid) with the pore-pressure evolution which allows a dynamic, porosity-

544 controlled deformation. Deformation is applied by introducing gravity, tectonic stretching

545 and high fluid pressure gradients in the system. The model fractures and heals where the 
546 mechanical properties of the new bonds can be varied. We tested the model by varying the

547 mechanical parameters of the system to investigate the evolving patterns as well as the stress

548 and porosity evolution. Our results showed that at the early stages of deformation the porosity

549 falls and increases after the maximum differential stress is obtained. Examining the influence

550 of the healing properties we concluded that the breaking strength of the healed bonds (veins)

551 has a major influence on the behavior of the system. The stronger the veins, (1) the less the

552 system fractures (i.e. fewer crack-seal cycles and open fractures), (2) the greater the stresses

553 and (3) the more limited the possible fluid flow. Strong veins can correspond to ore or even

554 quartz-filled veins, whereas a calcite vein would represent a typically weak one. The veins

555 elastic modulus, on the other hand, only plays a minor role in fracture patterns, does not

556 affect the stress states significantly and is only important in combination with other

557 mechanical parameters. In spite of the healing, the system in all cases reaches a somewhat

558 steady state (fracture saturation) by accommodating additional strain along pre-existing

559 fractures. Small-scale fractures link up to form larger fractures which eventually evolve to

560 through-going faults that drain the system. In a multilayered structure the seals only act as

561 stress barriers if they are soft (low elastic modulus) and lie close to the fluid source that

562 provides the high pressure gradients. Our results provide a good basis for understanding large

563 spatial and temporal scale fracturing and healing of a system characterized by the interplay

564 between tectonic stresses and pressure gradients.

565

566

567 Acknowledgements

568 This study is carried out within the framework of DGMK (German Society for Petroleum and

569 Coal Science and Technology) research project 718 "Mineral Vein Dynamics Modeling",

570 which is funded by the companies ExxonMobil Production Deutschland GmbH, GDF SUEZ 
571 E\&P Deutschland GmbH, RWE Dea AG and Wintershall Holding GmbH, within the basic

572 research programme of the WEG Wirtschaftsverband Erdöl- und Erdgasgewinnung e.V. We

573 thank the companies for their financial support and their permission to publish our results.

574 We also thank NEEDS-MIPOR, REALISE and the ITN FlowTrans for their support.

575

\section{References}

577 Adachi, J., Siebrits, E., Peirce, A., Desroches, J., 2007. Computer simulation of hydraulic

578 fractures. International Journal of Rock Mechanics \& Mining Sciences 44, 739-757.

579 Aochi, H., Poisson, B., Toussaint, R., Rachez, X., Schmittbuhl, J., 2013. Self-induced

580 seismicity due to fluid circulation along faults. Geophysical Journal International,

581 doi:10.1093/gji/ggt356.

582 Bai, T., Pollard, D.D., 2000. Fracture spacing in layered rocks; a new explanation based on

583 the stress transition. Journal of Structural Geology 22, 43-57.

584 Becker, A., Gross, M., 1996. Mechanism for joint saturation in mechanically layered rocks:

585 an example from southern Israel. Tectonophysics 257, 223-237.

586 Bethke, C.M., 1985. A numerical model of compaction-driven groundwater flow and heat

587 transfer and its application to paleohydrology of intracratonic sedimentary basins. Journal of

588 Geophysical Research 90, 6817-6828.

589 Bons, P.D., Elburg, M.A., Gomez-Rivas, E., 2012. A review of the formation of tectonic veins 590 and their microstructures. Journal of Structural Geology 43, 33-62.

591 Bons, P.D., Koehn, D., Jessel, M.W., 2008 . Microdynamics Simulation. Lecture Notes in 592 Earth Sciences 106, Springer, Berlin.

593 Brenner, S.L., Gudmundsson, A., 2004. Arrest and aperture variation of hydrofractures in 594 layered reservoirs. Geological Society of London Special Publications 231, 117-128.

595 Bruno, M.S., Nakagawa, F.M., 1991. Pore pressure influence on tensile fracture propagation 
in sedimentary rock. Journal of Rock Mechanics and Mining Sciences \& Geomechanics

597 Abstracts 28, 261-273.

598 Calò, M., Dorbath, C., Frogneux, M., 2013. Injection tests at the EGS reservoir of Soultz-

599 sous-Forêts. Seismic response of the GPK4 stimulations. Geothermics.

600 http://dx.doi.org/10.1016/j.geothermics.2013.10.007

601 Cobbold, P.R., Rodrigues, N. 2007. Seepage forces, important factors in the formation of

602 horizontal hydraulic fractures and bedding-parallel fibrous veins ('beef' and 'cone-in-cone').

603 Geofluids 7, 313-332.

604 Cook, J., Gordon, J.E., 1964. A mechanism fot the control of crack propagation in all brittle

605 systems. Proceedings of the Royal Society, London. Series A 282, 508-520.

606 Cooke, M.L., Simo, J.A., Underwood, C.A., Rijken, P., 2006. Mechanical stratigraphic

607 controls on fracture patterns within carbonates and implications for groundwater flow.

608 Sedimentary Geology 184, 225-239.

609 Cooke, M.L., Underwood, C.A., 2001. Fracture termination and step-over at bedding

610 interfaces due to frictional slip and interface opening. Journal of Structural Geology 23, 223-

611238.

612 Cornet, F. H., Valette, B.,1984. In situ stress determination from hydraulic injection test data.

613 Journal of Geophysical Research: Solid Earth 89(B13), 11527-11537.

614 Cox, S.F., 2005. Coupling between deformation, fluid pressures, and fluid flow in ore-

615 producing hydrothermal systems at depth in the crust. In: Hedenquist, J.W., Thompson,

616 J.F.H., Goldfarb, R.J., Richards, J.P. (Eds.), Economic Geology One Hundredth Anniversary

617 Volume. Society of Economy Geologists, Littleton, Colorado, 39-76.

618 Dahm, T., 2000. Numerical simulations of the propagation path and the arrest of fluid-filled

619 fractures in the Earth. Geophysical Journal International 141, 623-638.

620 Engelder, T., Lacazette, A., 1990. Natural hydraulic fracturing. In: Barton, N., Stephansson, 
622 Flekkøy, E.G., Malthe-Sørenssen, A., Jamtveit, B., 2002. Modeling hydrofracture. Journal of 623 Geophysical Research 107(B8), 2151.

624 Fyfe, W.S., Price, N.J., Thompson, A.B., 1978. Fluids in the Earth's crust. Elsevier, 625 Amsterdam.

626 Ghani, I., Koehn, D., Toussaint, R., Passchier, C.W., 2013. Dynamic development of 627 hydrofracture. Pure and Applied Geophysics, Springer, DOI 10.1007/s00024-012-0637-7.

628 Ghani, I., Koehn, D., Toussaint, R., Passchier, C. W., 2015. Dynamics of hydrofracturing and 629 permeability evolution in layered reservoirs. Frontiers in Physics 3, 67, DOI $63010.3389 /$ fphy.2015.00067 .

631 Goren, L., Aharonov, E., Sparks, D., Toussaint, R., 2010. Pore pressure evolution in 632 deforming granular material: A general formulation and the infinity stiff approximation. 633 Journal of Geophysical Research 115(B9), B09216.

634 Goren, L., Aharonov, E., Sparks, D., Toussaint, R., 2011. The mechanical coupling of fluid635 filled granular material material under shear. Pure and Applied Geophysics 168, 2289-2323. 636 Gross, M.R., Eyal, Y., 2007. Throughgoing fractures in layered carbonate rocks. GSA 637 Bulletin 119, 1387-1404.

$638 \mathrm{Gu}, \mathrm{H}$., Siebrits, E., 2008. Effect of formation modulus contrast on hydraulic fracture height 639 containment. SPE Production and Operations 23, 170-176.

640 Hu, J.-C., Angelier, J., 2004. Stress permutations: Three-dimensional distinct element 641 analysis accounts for a common phenomenon in brittle tectonics. Journal of Geophysical 642 Research 109(B9), B09403.

643 Hubber, M.K., Rubey, M.K., 1959. Role of fluid pressure in mechanics of overthrust faulting:

644 I. mechanics of fluid-filled porous solids and its application to overthrust faulting. Geological 645 Society of America Bulletin 70, 115-166. 
646 Hubbert, M.K., Willis, D.G., 1957. Mechanics of hydraulic fracturing, petroleum

647 transactions. AIME 210, 153-168.

648 Hunt, J.M., 1990. Generation and migration of petroleum from abnormally pressured fluid 649 compartments. AAPG Bulletin 74, 1-12.

650 Hurst, A., Cartwright, J. A., Duranti, D., Huuse, M., Nelson, M., 2005. Sand injectites: an 651 emerging global play in deep-water clastic environments. In: A. Doré and B. Vining, (Eds.),

652 Petroleum Geology: North-West Europe and Global Perspectives: Proceedings of the 6th 653 Petroleum Geology Conference, Geological Society (London) p. 133-144.

654 Johnsen, Ø., Toussaint, R., Måløy, K.J, Flekkøy, E.G., 2006. Pattern formation during air 655 injection into granular materials confined in a circular Hele-Shaw cell. Physical Review E 74, 656011301.

657 Johnsen, Ø., Toussaint, R., Måløy, K. J., Flekkøy, E. G., Schmittbuhl, J., 2008a. Coupled 658 air/granular flow in a linear Hele-Shaw cell. Physical Review E 77(1), 011301.

659 Johnsen, Ø., Chevalier, C., Lindner, A., Toussaint, R., Clément, E., Måløy, K. J., Schmittbuhl, 660 J., 2008b. Decompaction and fluidization of a saturated and confined granular medium by 661 injection of a viscous liquid or gas. Physical Review E 78(5), 051302.

662 Koehn, D., Arnold, J., Passchier, C.W., 2005. Fracture and vein patterns as indicators of 663 deformation history: a numerical study. Geological Society, London, Special Publications $664243,11-24$.

665 Mahrer, K. D., 1999. A review and perspective on far-field hydraulic fracture geometry 666 studies. Journal of Petroleum Science and Engineering 24, 13-28.

667 McDermott, C.I., Edlmann, K., Haszeldine, R.S., 2013. Predicting hydraulic tensile fracture 668 spacing in strata-bound systems. International Journal of Rock Mechanics \& Mining 63, 3966949.

670 McNamara, S., Flekkøy E.G., Måløy, K.J., 2000. Grains and gas flow: molecular dynamics 
671 with hydrodynamic interactions. Physical Review E 61, 4054-4059.

672 Mourgues, R., Cobbold, P.R. 2003. Some tectonic consequences of fluid overpressures and

673 seepage forces as demonstrated by sandbox modelling. Tectonophysics 376, 75-97.

674 Nermoen, A., Galland, O., Jettestuen, E., Fristad, K., Podladchikov, Y., Svensen, H., Malthe-

675 Sørenssen, A., 2010. Experimental and analytic modeling of piercement structures. Journal of

676 Geophysical Research: Solid Earth 115(B10).

677 Niebling, M. J., Flekkøy, E. G., Måløy, K. J., Toussaint, R., 2010a. Sedimentation

678 instabilities: impact of the fluid compressibility and viscosity. Physical Review E 82(5),

679051302.

680 Niebling, M. J., Flekkøy, E. G., Måløy, K. J., Toussaint, R., 2010b. Mixing of a granular layer 681 falling through a fluid. Physical Review E 82(1), 011301.

682 Niebling, M. J., Toussaint, R., Flekkøy, E. G., Måløy, K. J., 2012. Dynamic aerofracture of 683 dense granular packings. Physical Review E 86(6), 061315.

684 Oliver, J., 1986. Fluid expelled tectonically from orogenic belts: their role in hydrocarbon 685 migration and other geologic phenomena. Geology 14, 99-102.

686 Oliver, N.H.S., 1996. Review and classification of structural controls on fluid flow during 687 regional metamorphism. Journal of Metamorphic Geology 14, 477-492.

688 Olson, J.E., Laubach, S.E., Lander, R.H., 2009. Natural fracture characterization in tight gas 689 sandstones: Integrating Mechanics and diagenesis. AAPG Bulletin 93, 1535-1549.

690 Putnis, A.,Putnis, C.V., 2007, The mechanism of reequilibration of solids in the presence of a 691 fluid phase. Journal of Solid State Chemistry, 180 (5), 1783-1786.

692 Putnis, A.,Austrheim, H., 2010. Fluid-induced processes: Metasomatism and metamorphism 693 Geofluids, $10(1-2), 254-269$.

694 Rodrigues, N., Cobbold, P. R., Loseth, H., 2009. Physical modelling of sand injectites.

695 Tectonophysics, 274(3-4), 610-632. 
696 Rozhko, A. Y., Podladchikov, Y. Y., Renard, F., 2007. Failure patterns caused by localized rise

697 in pore-fluid overpressure and effective strength of rocks. Geophysical Research Letters, 698 34(22), L22304.

699 Rozhko, A. Y., 2010. Role of seepage forces on seismicity triggering. Journal of Geophysical 700 Research: Solid Earth, 115(B11).

701 Scholz, C.H., 2002. The mechanics of earthquakes and faulting, 2nd edn. Cambridge 702 University Press, Cambridge.

703 Shalev, E., Calò, M., Lyakhovsky, V., 2013. Formation of damage zone and seismic velocity 704 variations during hydraulic stimulation: numerical modelling and field observations.

705 Geophysical Journal International, 195(2), 1023-1033.

706 Shapiro, S. A., Dinske, C.,2009. Fluid-induced seismicity: Pressure diffusion and hydraulic 707 fracturing. Geophysical Prospecting, 57(2), 301-310.

708 Simonson, E.R., Abou-Sayed, A.S., Clifton, R.J., 1978. Containment of massive hydraulic 709 fractures. SPE Journal 18, 27-32.

710 Smith, M.B., Bale, A.B., Britt, L.K., Klein, H.H., Siebrits, E., Dang, X., 2001. Layered 711 modulus effects on fracture propagation, proppant placement, and fracture modeling. Paper 712 SPE 71654 presented at the SPE Annual Technical Conference and Exhibition, New Orleans, 71330 September - 3 October 2001.

714 Swarbrick, R.E., Osborne, M.J., Yardley, G.S., 2002. Comparison of overpressure magnitude 715 resulting from the main generating mechanisms. In: Huffman, A.R., Bowers, G.L. (Eds.), 716 Pressure Regimes in Sedimentary Basins and Their Prediction, 76, AAPG Memoir, 1-12. 717 Tang, C.A., Liang, Z.Z., Zhang, Y.B., Chang, X., Tao, X., Wang, D.G., Zhang, J.X., Liu, J.S., 718 Zhu. W.C., Elsworth, D., 2008. Fracture spacing in layered materials: a new explanation 719 based on two-dimensional failure process modeling. American Journal of Science 308, 49-72. 720 Tenthorey, E., Cox S.F., Todd, H.F., 2003. Evolution of strength recovery and permeability 
721 during fluid-rock reaction in experimental fault zones. Earth and Planetary Science Letters 722 206, 161-172.

723 Tzschichholz, R., Herrmann, H.J., Roman, H.E., Pfuff, M., 1994. Beam model for hydraulic 724 fracturing. Physical Review B 49, 7056-7059.

725 Vinningland, J. L., Johnsen, Ø., Flekkøy, E. G., Toussaint, R., Måløy, K. J., 2007. Granular 726 Rayleigh-Taylor Instability: Experiments and simulations. Physical review letters, 99(4), 727048001.

728 Wangen, M., 2011. Finite element modelling of hydraulic fracturing on a reservoir scale in 729 2D. Journal of Petroleum Science and Engineering 77, 274-285.

730 Zoback, M.D., Harjes, H.-P., 1997. Injection-induced earthquakes and crustal stress at 9 km 731 depth at the KTB deep drilling site, Germany. Journal of Geophysical Research: Solid Earth 732 102(B8), 18477-18491. 